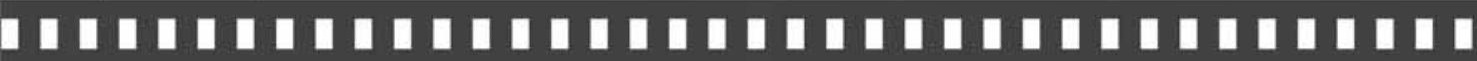

\author{
A arquitetura de defesa no Brasil Colonial
}

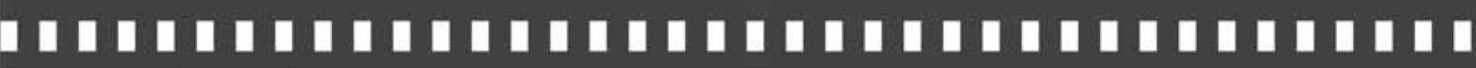

José de Arimathéia Cordeiro Custódio 


\title{
A arquitetura de defesa no Brasil Colonial
} The defense architecture in Colonial Brazil

\author{
JosédeArimathéia Cordeiro Custódio*
}

\begin{abstract}
Resumo: Este artigo discorre sobre o estilo arquitetônico colonial brasileiro, cujas raízes medievais enfatizavam o caráter defensivo das construções, tanto militares quanto eclesiásticas. Ilustra a reflexão a partir de registros visuais fotográficos que valorizam a arquitetura de defesa em sua angulação e enquadramento. Recupera a história de tais monumentos históricos e suas funções de defesa do território brasileiro, à época alvo de disputas mercantis.
\end{abstract}

Palavras-chaves: Arquitetura colonial. Defesa. Fortalezas. Fotografia.

\begin{abstract}
This article discusses the Brazilian colonial architecture style, which medieval roots emphasized the defensive character of the buildings, such as the militar as the ecclesiastic ones. It arises from photographic visual records which valorize the defense architecture in its angles and frames. It recovers the history of those historic monuments and their defense functions of Brazilian territory, that was, at that time, a target of commercial disputes.
\end{abstract}

Keywords: Colonial architecture. Defense. Fortress. Photography.

* Professor universitário. Doutor em Estudos da Linguagem pela Universidade Estadual de Londrina. Especialista em Fotografia e em História Social pela mesma instituição. E-mail: jotacustodio@uol.com.br 


\section{Introdução}

Em termos históricos, considera-se que o período colonial brasileiro vai de 1500 (chegada da esquadra de Pedro Álvares Cabral) até 1822 (independência). Naturalmente, a arquitetura encontrada em tal período possui características europeias, quase totalmente portuguesas. É evidente que mesmo Portugal trouxe à colônia traços de outras influências, como a árabe. Em conventos do Nordeste, encontramos azulejos e torres que lembram minaretes.

As marcas estilísticas são, contudo, muito mais ricas. Adotando materiais locais, conforme as possibilidades sócio-econômicas de cada lugar, os colonizadores construíram edifícios e espaços com traços medievais, renascentistas, maneiristas, barrocos, rococós, até chegar ao neoclássico, estilo forte já do Período Imperial (1822-1889). Embora cada estilo tenha uma estética própria, com signos e sentidos característicos, no Brasil a transição e a convivência entre eles acabaram gerando, em alguns casos, debates inacabados entre estudiosos da arte e da arquitetura.

Porém, o que é indiscutível é a importância do legado arquitetônico colonial brasileiro, encontrado principalmente no Nordeste e Sudeste do país, e especialmente ao longo do litoral, no caso das construções militares.

É destas construções que trata este estudo. O objeto de reflexão - a arquitetura colonial - tem aqui uma de suas dimensões funcionais destacada: o caráter de defesa, herdado da não muito distante Idade Média. No caso das fortificações costeiras, o objetivo era bem claro: proteger o território de invasores estrangeiros - e houve muitos: espanhois em Santa Catarina; holandeses em Pernambuco; franceses no Rio de Janeiro. Logo, os muros, guaritas, seteiras e fossos deveriam garantir a resistência e 0 ataque às forças inimigas.

Da mesma forma, mas com um componente a mais (a espiritualidade), os conventos construídos no período colonial brasileiro também pareciam fortalezas, erguidos para proteger não somente dos eventuais invasores pagãos, mas também para separar os religiosos dos perigos diabólicos do mundo exterior. Assim, os claustros e os pátios 
internos se tornaram característicos dos conventos, desde os primeiros, fundados no Egito por Santo Antão, no século III, até os atuais, como a Abadia da Ressurreição em Ponta Grossa (Paraná).

A arquitetura dos mosteiros beneditinos medievais - modelo para toda a cristandade - já trazia todo um simbolismo espacial. Tomemos como exemplo a Abadia de Sankt Gallen (Suíça), do século IX. A Igreja, claro, fica no centro. A leste, os aposentos do Abade, representante maior de Deus na Terra. Depois, os demais monges, formando uma milícia sagrada. ABiblioteca fica entre a igreja e o claustro, pois o conhecimento está entre a divindade e o recolhimento. A leste ficam também a escola, oficina de escrita e ateliê de arte, que são funções espirituais. Já lugares como o refeitório, claustro dos noviços, estábulos e latrinas, muito mais ligados a profanos e coisas mundanas, ficam no lado oeste. As sepulturas estão a leste, do lado da aurora, que simboliza a ressurreição. A oeste fica a Hospedaria, pois é o lugar dos homens ligados ao mundo, que estão apenas de passagem.

De volta ao Brasil, Tirapeli (2006, p.7) afirma que no período colonial predominou o estilo maneirista, barroco e rococó, “presentes em construções militares, civis e religiosas no litoral, no interior, e em Minas Gerais, principalmente, a partir do século 18”. E acrescenta: “Logo após o Descobrimento do Brasil, as primeiras construções realizadas foram as fortalezas, erguidas com o objetivo de defesa das vilas e cidades litorâneas. Os arquitetos eram militares e, posteriormente, padres jesuítas, que fundaram vilas e construíram igrejas e conventos”. Vilas para ocupação e igrejas para "manter a fé cristã entre os colonizadores e promover a catequese dos índios”, diz o autor (2006, p.10).

Na mesma direção orientam Tenório, Almeida e Dantas (2006, p.12):

Ao chegar, os colonizadores iniciaram a ocupação da terra e preocuparam-se, antes de qualquer coisa, em defender o território tomado e ensinar sua cultura aos nativos [...]. Ao se estabelecer aqui, após as expedições exploradoras, as primeiras construções edificadas, que são igualmente as primeiras manifestações 
artísticas dos portugueses no novo território, são os fortes e as igrejas. A primeira, para assegurar o domínio de El-rei, o segundo, para render devoção a Deus. Um para defender os homens na Terra, o outro para proporcionar a entrada dos homens no céu.

Como bem anota Campos (2006, p.21), “o homem geralmente edifica a casa e suas dependências em conformidade com a experiência e os valores sociais de seu tempo". É sobre um tempo de necessidade de defesa e afirmação de valores (monárquicos e católicos), portanto, que repousa este estudo.

\section{Características da Arquitetura Colonial}

Praticamente por três décadas, não houve interesse (leia-se mercantil) dos colonizadores portugueses no território brasileiro. Foi com o estabelecimento das Capitanias Hereditárias, justamente a partir da terceira década do século XVI, que teve início a atividade arquitetônica no Brasil com alguma expressão. Igarassu e Olinda em Pernambuco, e São Vicente, em São Paulo, são desta década. Salvador, fundada com várias características do pensamento medieval, é de 1549. Sobre esta última, Baeta (2010, p.349) fala da

[...] necessidade de o núcleo urbano se 'apertar' entre seus limites de proteção: acidentes naturais, como a falha geológica da primeira capital do Brasil, ou barreiras edificadas, como as muralhas que vão cercar as cidades lusas e alguns núcleos importantes do litoral brasileiro".

É preciso, contudo, destacar a existência de duas construções em solo baiano de grande importância histórica, muito apropriadas para este estudo. Uma delas é o único castelo feudal das Américas, o Castelo Garcia D’Ávila, na Praia do Forte, cuja construção se iniciou em 1551, embora tenha ficado pronto apenas sete décadas depois, e esteja em restauração há anos. 
A segunda é o Mosteiro de São Bento de Salvador, de 1582, o primeiro em terras americanas. Atualmente, a exemplo dos mosteiros beneditinos de São Paulo e Rio de Janeiro, o soteropolitano foi totalmente cercado pela cidade. Não faltaram, aliás, tentativas do poder secular de derrubá-lo, mas ele sempre resistiu. Mas, mesmo encurralados entre tráfego intenso e multidões de transeuntes, tais mosteiros ainda conseguem ser ilhas de silêncio, contemplação e atividades espirituais. Suas paredes ainda defendem seus moradores do alarido profano.

O mesmo ocorreu com muitas fortificações coloniais, hoje transformadas - para deleite dos apreciadores de História - em atrações turísticas. Diversas acabaram como os mosteiros - engolidas pelo crescimento urbano. Um forte em Salvador (São Pedro), um no Rio de Janeiro (Copacabana) e dois em Recife (Brum e Cinco Pontas) são alguns exemplos. Várias são propriedade das Forças Armadas e cuidadas por elas. É o caso da Fortaleza de Santa Cruz (Niterói), com sua cor branca característica. Em Governador Celso Ramos (SC), a Universidade Federal de Santa Catarina está envolvida na preservação da Fortaleza de Anhatomirim. Em Itamaracá (PE), até um artesão, expresidiário, comprometeu-se com a restauração do Forte Orange.

Segundo Tirapeli (2006, p.13),

Para defenderem a nova terra contra invasores e índios, os portugueses construíram fortalezas em vários pontos da costa litorânea. Muitas delas resistiram ao tempo e ainda podem ser conhecidas de perto. Salvador, a antiga capital colonial, é a cidade com o maior número de fortificações, que estão ao redor da Baía de Todos os Santos. Devido à proximidade com os espanhóis, a ilha mais fortificada é a de Santa Catarina, onde hoje está a cidade de Florianópolis. No litoral paulista também existem muitos fortes, e em Bertioga está o mais antigo deles, chamado São João, onde Hans Staden serviu aos portugueses em 1537. Entretanto, a maior fortaleza do Brasil não fica no litoral, mas sim em Rondônia, e se chama Real Forte do Príncipe da Beira. Situada na margem direita do rio Guaporé, foi construída a mando do Marquês de Pombal, na segunda metade do século 18, para marcar a fronteira portuguesa na Amazônia. 
Enfim, fortificações, igrejas e conventos eram aspecto determinante e essencial na paisagem urbanística colonial. As fortalezas ficavam em pontos elevados da encosta e frequentemente em uma necessária passagem de embarcações. Não raro eram as construções que formavam um complexo de defesa. Em Santa Catarina, as fortalezas de Ratones, Anhatomirim e São José da Ponta Grossa formavam um triângulo defensivo para o invasor que vinha do norte. Na Baía da Guanabara, Santa Cruz e São João se localizam no ponto mais estreito.

Acrescentando-se à estratégia de avistar o inimigo de longe um sentido espiritual, as construções religiosas também eram erguidas, com frequência, em lugares bem altos. A Igreja de Nossa Senhora da Conceição, em Santa Cruz Cabrália (BA), pode ser vista de longe, do mar ou do rio - a perspectiva do invasor. A Igreja de Santo Antonio, a mais antiga de Aracaju, fica num ponto alto, de onde se vê quase toda a cidade. Ainda em Aracaju, a Igreja de São Judas Tadeu, onde há um convento franciscano, também fica em um ponto elevado.

Mas o melhor exemplo é o Convento da Penha, em Vila Velha (ES). Aliás, toda igreja que leva este nome (Penha, que vem de penhasco) fica muito alta. A tradição popular, inclusive, conta que o convento capixaba ficou lá em cima por causa da própria santa, cuja imagem desaparecia à noite da pequena capela (num ponto mais baixo do morro) e amanhecia no alto, onde hoje realmente está o convento.

Sabe-se que muitos dos primeiros arquitetos do período colonial eram, até por força das circunstâncias, religiosos e militares. Havia também aqueles de conhecimento prático - mestres-de-obras, pedreiros, carpinteiros. Todos contribuíram, com seu conhecimento técnico e acervo simbólico cultural, na construção dos edifícios arquitetônicos coloniais, militares e eclesiáticos. Entre os construtores religiosos, muitos vieram, primeiro, com os jesuítas (os missionários das Grandes Navegações portuguesas), depois os beneditinos (com seus mosteiros) e franciscanos (igrejas com um grande cruzeiro na frente). Tirapeli (2006, p.20) o diz claramente: "o estilo chegou ao Brasil por meio dos artistas das ordens religiosas, principalmente os jesuítas, franciscanos e beneditinos”. 
Vale citar que Antonio de Sant'Anna Galvão, ou Frei Galvão (17391822), foi um franciscano, nascido em Guaratinguetá (SP), exemplo desta tradição: projetou o Mosteiro da Luz, em São Paulo. Por esta razão é o padroeiro dos arquitetos e construtores.

As primeiras igrejas construídas no Brasil possuem fachada simples, no chamado "estilo chão", ou maneirista. Traz do Renascimento tardio a preferência por linhas geométricas simples, e o estilo maneirista, de visão prática, simplifica as formas. Conforme Tirapeli (2006, p.7),

\section{[...] as construções do século 16 e início do 17, denominadas maneiristas, possuem uma arquitetura simples, que se torna mais complexa no século 18 , quando apresentam fachadas curvas feitas em pedra, e interiores ricamente decorados com objetos de arte.}

No livro História da Arte (2008, p.11), está assinalado que a arquitetura maneirista, “como cumpre um propósito mais estritamente funcional, existe uma possibilidade menor de se permitir caprichos estéticos".

Ou ainda, nas palavras de Argan (2005, p.136), o Maneirismo é o "triunfo da prática sobre a teoria”, mas “a prática que, no âmbito religioso, começava a ser revalorizada como geradora de espiritualidade".

A importância das capelas e igrejas coloniais repousa, sobremaneira, do seu simbolismo. Como assinalam Tenório, Almeida e Dantas (2006, p.13), elas eram "o lugar de refúgios, mais que as fortificações”.

A decoração maneirista é espartana e a predominância é de linhas quadrangulares e retas. Há presença de azulejos. Mas, em essência, trata-se de ser funcional e econômico, pois se tratava de comunidades incipientes, num território novo, ainda não explorado, e sujeito a invasões. Neste contexto de instabilidade e insegurança, não havia condições para ostentação de riqueza. Há algumas igrejas deste estilo quinhentista no Nordeste brasileiro, como em Porto Seguro (Igreja da Misericórdia), Igreja de São Cosme e Damião (Igarassu), Igreja da Graça (Olinda), além da Capela de Santa Luzia (Vitória), extremamente modesta em seu exterior. 
Tenório, Almeida e Dantas (2006, p.73) explicam como se escolhia o sítio para erguer as igrejas:

Por uma questão estratégica, de visibilidade de poder e de defesa, o lugar escolhido para a construção da igreja costumava ser uma edificação natural e ampla, com espaço largo para a formação de uma praça na frente do Templo, que facilitasse as práticas religiosas e garantisse a expansão do núcleo em seu entorno. A praça logo se constituía reunindo também a Casa da Câmara, em uma aproximação institucional que bem representava a convivência do poder eclesiástico com o poder político.

Já os conventos, em sua grande parte em estilo barroco, e dentro do espírito de seu tempo histórico, retomaram ideais medievais que influenciaram também sua arquitetura, mediante paredes reforçadas e claustros proibidos para não religiosos, ou seja, não iniciados.

Sabe-se que o barroco é o movimento artístico da Contra-Reforma Católica, daí sua suntuosidade e rebuscamento. Era a Igreja de Roma expressando sinais de poder através de signos visuais e catequéticos. Muito ouro para provar a realeza e poder temporal; riqueza de detalhes para mostrar a inteligência e conhecimento; escalas gigantescas para demonstrar ligação com o divino; contrastes de luz e sombra com função pedagógica, reafirmando a efemeridade da existência terrena. Para Campos (2006, p.7) “o Barroco não foi apenas um estilo artístico, mas uma visão de mundo envolvendo formas de pensar, sentir, representar, comportar-se, acreditar, criar, viver e morrer".

Tirapeli (2006, p.20/22) lembra que

[...] como tudo no Brasil estava por construir e Portugal veio também para catequizar, a Igreja teve um papel importante na formação da cultura colonial. [...] As igrejas ficavam sempre muito visíveis, e os conventos ficavam nas saídas das cidades ou estas se desenvolviam ao seu redor. [...] Era um local onde se respirava a cultura e o sentido de construção de uma nova nação longe da Coroa. As figuras de Deus e do rei se confundiam, pois a este se atribuía um poder considerado como recebido diretamente de Deus. 
No claustro, os religiosos se protegem das tentações e podem se concentrar na oração, estudos e trabalho em ritmo monástico. As paredes e muros os defendem da influência secular, ao mesmo tempo em que constituem um santuário também para os fieis. É na Igreja que podiam se refugiar em dias de ataque inimigo ou tempestades, pois a Igreja é o símbolo da solidez e perenidade, seja em seus atributos simbólicos, seja na sua arquitetura de defesa.

De uma certa forma, os dois estilos coloniais fazem memória aos dois estilos medievais - guardadas as devidas diferenças, claro. Na Alta Idade Média (séculos V-XI), o estilo românico fez das igrejas verdadeiras fortalezas: janelas que se parecem seteiras e paredes de pedra que parecem que jamais cairão. No interior, a Igreja era escura. No exterior, eram tempos de escuridão; tempos de invasões bárbaras. Já na Baixa Idade Média, o estilo gótico encontrou uma Europa cristianizada e estável. O avanço do conhecimento arquitetônico possibilitou então a construção de grandes janelas com vitrais. Ou seja, agora a luz entrava à vontade. Os tempos de escuridão haviam passado.

Tirapeli (2006, p.22) descreve a organização espacial urbana em que as igrejas se inseriam:

As igrejas foram construídas voltadas para a praça principal, e na sua fachada, na maioria das vezes, existem duas torres. Entre elas fica o corpo central, que apresenta no alto uma estrutura denominada triângulo frontão, que pode ser curvo ou reto.

No Brasil, o estilo maneirista, num contexto histórico de Reforma, era prático e funcional. O importante era demarcar o espaço católico da colônia incipiente. Depois, num território com soberania portuguesa e católica consolidada, o barroco teve espaço para se projetar livremente. De um lado, exibiu grandeza e ostentação. Mas, de outro, não deixava de advertir sobre o constante perigo das tentações do mundo material, das heresias de povos protestantes, da fugacidade da vida terrena e das promessas de salvação para o espírito vigilante e fiel. 
Sobre o florescimento do estilo, Campos (2006, p.7) aponta que nas monarquias absolutistas católicas, nas quais se inclui Portugal, o barroco encontrou as melhores condições para se desenvolver, ganhando "magnificência, monumentalidade e requinte, suscitando nos súditos e devotos emoção e verdadeiro deslumbramento”. Este estilo, claro, chegou ao Brasil. Tirapeli (2006, p.16) confirma, referindo-se à arquitetura religiosa: "Várias ordens religiosas vieram para o Brasil no período colonial e construíram igrejas e conventos em pedra semelhantes aos que existiam em Portugal."

Quanto às construções militares, também parecem se assemelhar, em alguns aspectos, com a história medieval das fortificações. O Forte de São Tiago (Bertioga/SP), por exemplo - o primeiro em solo brasileiro começou com uma paliçada de madeira, tal como os castelos europeus da Alta Idade Média. Muros e paredes e alvenaria vieram depois. Ovos e óleo de baleia eram alguns dos materiais usados para dar liga e resistência às grossas paredes.

Tirapeli (2006, p.39) destaca a Fortaleza da capital potiguar:

[...] a Fortaleza dos Reis Magos é a mais conservada e completa construção militar brasileira do período colonial. Fica em Natal (RN) e começou a ser construída ainda no século 16, em 1598.0 projeto é semelhante ao do Forte de Jesus de Mombaça, em Portugal, e revela as mais avançadas técnicas de defesa da época. A Fortaleza dos Reis Magos tem valor simbólico desde que foi construída, pois mostrava o poderio da Coroa luso-espanhola. Em 1631, caiu em poder dos holandeses e passou a se chamar Castelo Ceulen, sendo retomada em 1654. Atualmente a fortaleza abriga o Museu de Arte popular do Rio Grande do Norte, Fundação José Augusto.

Os fortes foram construídos em formatos quadrangulares ou poligonais (estrela). Às vezes, o relevo do local forçava uma adaptação e fuga do formato regular, gerando curiosidades. O Forte de Cinco Pontas de Recife, por exemplo, tem apenas quatro - intercorrências da construção. As guaritas com seteira são típicas da arquitetura defensiva portuguesa. 
Não faltavam a capela, os portais, o paiol, os alojamentos, as aberturas para canhões e, eventualmente, elementos como fosso, poço, cisterna e sistema de captação de água de chuva.

Quase todos os fortes ficam em solo firme, mas uma exceção deve ser apontada: o Forte de São Marcelo, na Baía de Todos os Santos, a cerca de 300 metros da praia. É do século XVII e o único em formato circular em todo o Brasil, tendo sido inspirado, afirmam alguns, na Torre do Bugio (foz do rio Tejo, Portugal).

Cabe ainda mencionar outras construções militares com algum elemento peculiar e distintivo. O Real Forte Príncipe da Beira, em Rondônia, é a fortaleza mais ao interior, longe do oceano, localizada na fronteira com a Bolívia, à margem direita do rio Guaporé. Também na Amazônia, há a Fortaleza de São José de Macapá, à margem esquerda do rio Amazonas, numa área total de 84 mil metros quadrados. Ambos possuem formato de estrela com quatro pontas, mas não são tão antigos, datando da segunda metade do século XVIII. AFortaleza de Santa Cruz, em Niterói, assemelhase a uma pequena cidade: possui escadas, túneis, celas e calabouços, capela e até ruas e vielas, quase formando um labirinto (ou uma pequena vila medieval). Por fim, vale observar que todas as regiões do Brasil possuem fortificações, embora nem todas visitadas ou conhecidas. Só não foram citadas até aqui exemplos no Centro-Oeste, mas os dois estados de Mato Grosso possuem as suas. Só que não são tão antigas.

\section{Um olhar claustrófilo}

Os monumentos históricos brasileiros mencionados neste artigo já foram fotografados incontáveis vezes, e basta digitar seus nomes num programa de busca de imagens e lá estarão eles, nos mais variados ângulos, enquadramentos, detalhes e, para o bem ou para o mal, níveis de qualidade fotográfica.

Apesar da importância da competência técnica, aqui é mais importante o olhar gerador de sentidos; a tradução que a fotografia faz do 
olhar daquele que a tirou. No caso, um olhar claustrófilo, em busca de uma imagem que reforce a arquitetura de defesa e o imaginário medieval da qual ela se origina. Trata-se da busca de signos de solidez, força e perenidade. Alguns ângulos ou detalhes nem permitem identificar facilmente a construção a que se refere, e é necessária a legenda. Mas ilustram com propriedade a reflexão sobre o estilo arquitetônico e sua função de proteção e defesa.

A figura 1 mostra parte do Convento da Penha, de Vila Velha (ES), num ângulo de contra-mergulho. É a perspectiva do ser humano, pequeno e inferior, que sobe o morro para adentrar seus espaços seguros e protegidos. Erguido sobre rocha sólida, assemelha-se a uma construção militar, a uma fortaleza medieval, pois, deste ângulo, não exibe nenhuma cruz, nenhum signo cristão. Só se vê paredes e muros sólidos.

Figura 1 - Convento da Penha - Vila Velha (ES)

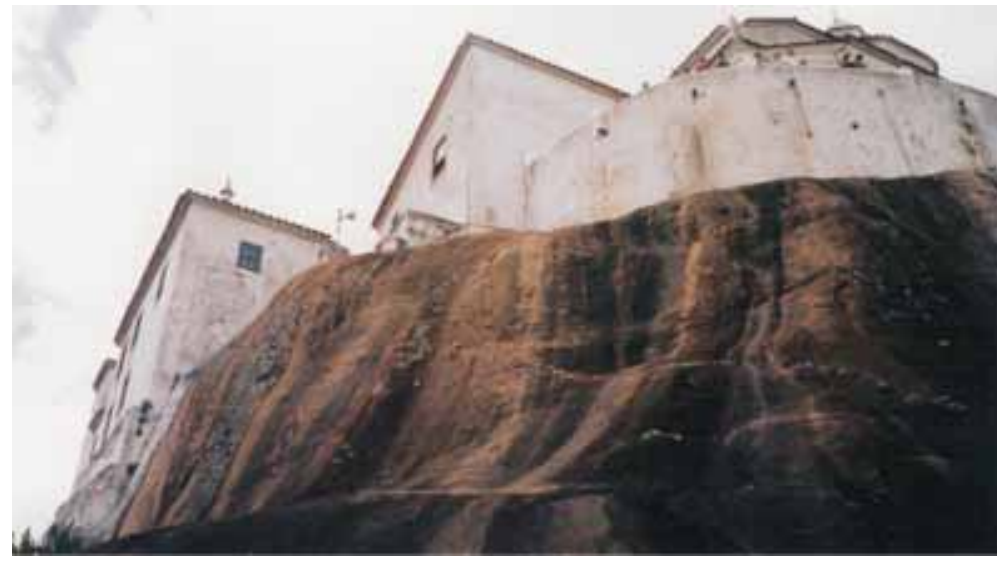

Fotografia: José de Arimathéia C. Custódio (março de 2002) Fonte: Acervo pessoal do fotógrafo

A figura 2 traz um detalhe do claustro do Convento de São Francisco, em Olinda (PE). O enquadramento e as linhas da imagem reforçam a ideia de restrição espacial. Parece a visão de uma janela. As paredes enegrecidas e as sombras nos dois pisos acentuam a sensação de estar num lugar antigo e apertado, sem saída a não ser para o alto. Faz parte da 
doutrina religiosa: o único lugar a se aspirar é o Céu, mas apenas com a alma. A Terra é pedra e pó, que deteriora. Como não há nenhuma pessoa na fotografia, o leitor se sente ainda mais sozinho em sua contemplação da imagem. $\mathrm{O}$ alto da torre exibe detalhes que mostram a influência mourisca na arquitetura colonial portuguesa.

Figura 2 - Claustro do Convento de S. Francisco (Olinda-PE)

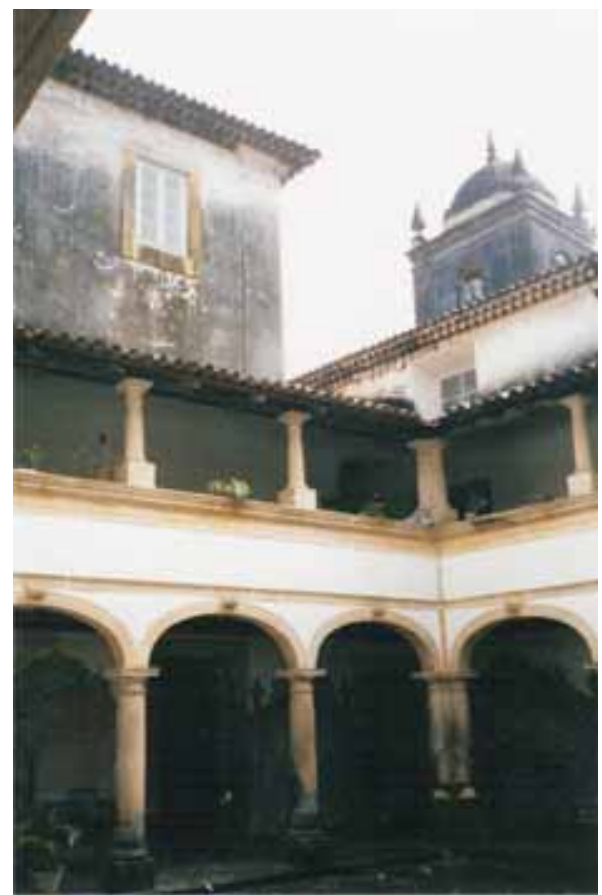

Fotografia: José de Arimathéia C. Custódio (julho de 2000) Fonte: Acervo pessoal do fotógrafo

A figura 3 é um flagrante de alguns turistas numa das vielas da Fortaleza de Santa Cruz, em Niterói (RJ). Um passeio guiado por um militar, que serve na Fortaleza, mostra alguns dos principais pontos da fortificação. Parte da área é reservada, mas os visitantes podem andar por corredores, escadas, túneis, e conhecer a capela de Santa Bárbara (padroeira dos artilheiros), as baterias com os canhões, o cantinho das execuções por fuzilamento (onde uma mina d’água de origem inexplicada 
lavava o sangue dos mortos) e a Cova da Onça, um pequeno cômodo destinado a suplícios de prisioneiros, que gemiam e, de longe, pareciam uivos de onça.

Figura 3 - Fortaleza de Santa Cruz (Niterói-RJ)

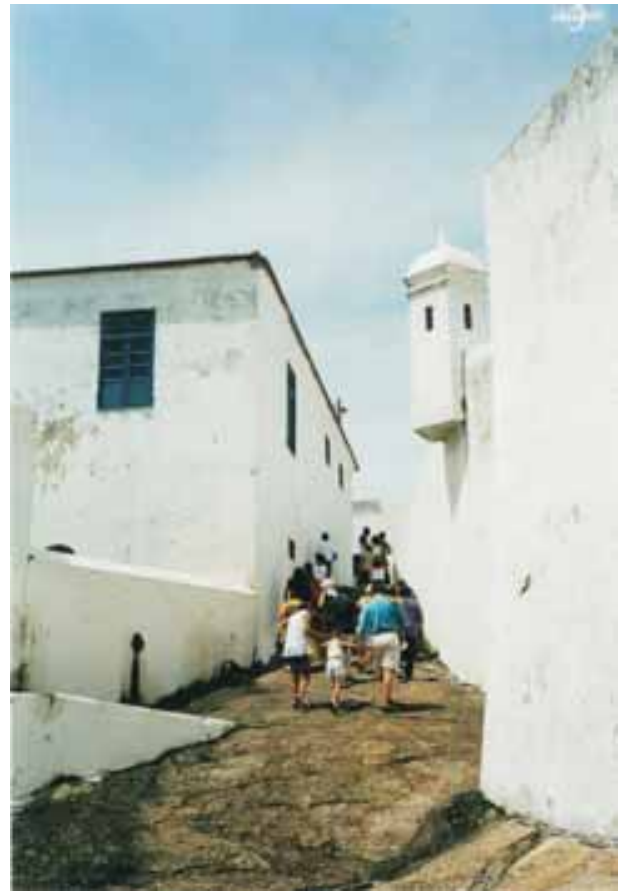

Fotografia: José de Arimathéia C. Custódio (fevereiro de 2001) Fonte: Acervo pessoal do fotógrafo

$\mathrm{Na}$ imagem, percebe-se a construção em linhas retas e quadrangulares, ou seja, simples e práticas. Muita parede e poucas janelas, todas altas. A guarita éum exemplo ilustrativo do estilo militar das fortalezas portuguesas coloniais. As paredes são altas e a viela é estreita e em aclive, uma organização que dificulta a ação de invasores e favorece a defesa do local. As vielas e becos não obedecem a um traçado geométrico regular, de forma que, sem o guia, um visitante tem grandes chances de tomar 0 caminho errado e até andar em círculos - mais um mecanismo de defesa. O branco indica o pertencimento ao Exército. 
A figura 4 lembra a imagem da figura 2, e de fato se trata de um outro convento franciscano. Mas, desta vez, é o Convento de Santo Antônio, na capital paraibana. A ideia, porém, foi a mesma: fazer uma imagem do claustro que reforçasse a sensação de lugar fechado, isolado do mundo exterior. Os únicos signos perceptíveis levam à religião. Estão lá novamente a influência mourisca nas torres e os arcos característicos dos claustros ibéricos. $\mathrm{O}$ arco escuro, à esquerda, moldura parte da imagem e reforça a noção de limitação do espaço terreno. Mais uma vez, há um jogo de luz e sombra, na tentativa de deixar a imagem mais barroca e provocar as mesmas sensações que o estilo artístico contra-reformador católico. Não há cores vivas e quentes na fotografia, mas também não deixa de haver beleza na simetria e formas. E onde a beleza é percebida, a existência de vida é intuída-mesmo que, no caso, seja uma vida terrena peregrina com vistas a uma vida eterna e plena no reino espiritual.

Figura 4 - Convento de Santo Antônio (João Pessoa- PB)

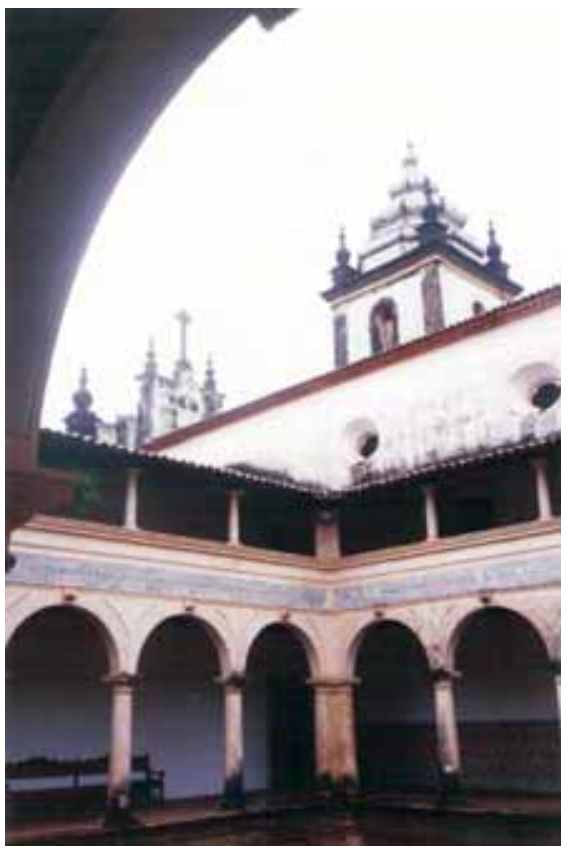

Fotografia: José de Arimathéia C. Custódio (julho de 2000) Fonte: Acervo pessoal do fotógrafo 
A figura 5 traz uma imagem de uma das guaritas da Fortaleza da Ilha de Ratones, em Santa Catarina. Pode-se ver, pelo contraste, que há uma pequena janela (seteira), pela qual o vigia pode ver a aproximação de embarcações, pelo mar. Dentro da guarita, o vigia não pode ser visto nem atingido, salvo por tiro de canhão, que alertaria a todos. As guaritas eram dispostas de modo que de uma se avista outra, estabelecendo um perímetro de observação em todas as direções, sem pontos cegos.

Figura 5 - Guarita da Fortaleza de Ratones (Florianópolis- SC)

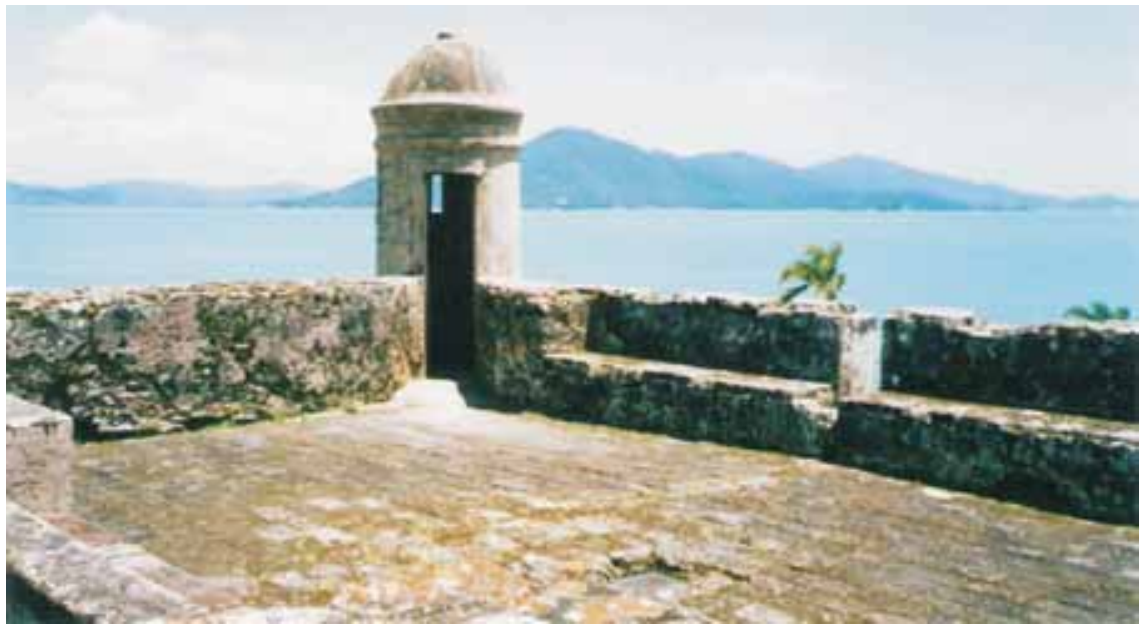

Fotografia: José de Arimathéia C. Custódio (dezembro de 2004)

Fonte: Acervo pessoal do fotógrafo

A figura 6 é um exemplo da arquitetura das primeiras igrejas no Brasil, de linhas mais simples e funcionais. A fotografia é da Igreja da Misericórdia, no conjunto histórico antigo de Porto Seguro (BA). Uma das mais antigas do Brasil, a igreja tem uma única entrada na frente e não tem janelas laterais, o que indica que também serve para proteção e defesa no caso de uma invasão, pois se torna um espaço defensável. Além disso, embora a imagem não mostre, a igreja se situa num plano elevado, vários metros acima do nível do mar, num mirante natural. 
Figura 6 - Igreja da Misercórdia (Porto Seguro - BA)

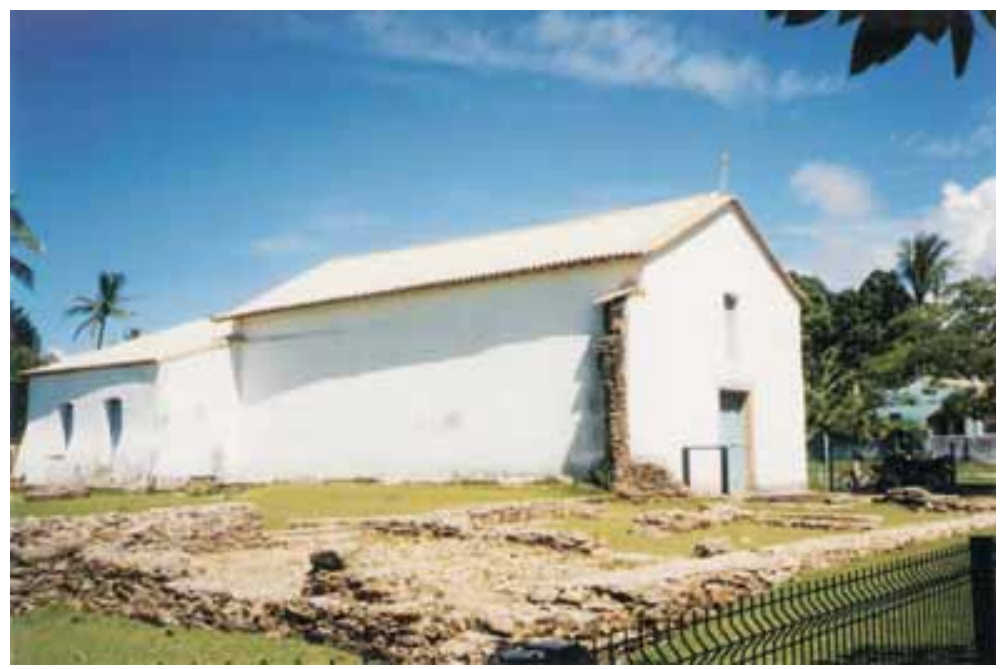

Fotografia: José de Arimathéia C. Custódio (abril de 2003) Fonte: Acervo pessoal do fotógrafo

A figura 7 mostra um detalhe da fachada externa do Forte de São Diogo, em Salvador. Localizado na ponta da Baía de Todos os Santos, em posição diametralmente oposta ao Farol da Barra, o pequeno Forte é cercado por uma praça verde. A imagem captada valoriza o conjunto de defesa, com a muralha e a guarita com finas seteiras em primeiro plano. É fácil perceber que, para um inimigo que se aproxima, éimpossível saber se há um vigia, assim como incapacitá-lo. Mas, ao contrário, um invasor pode ser facilmente atingido por um guarda lá dentro posicionado. Mais altas ainda, as janelas do edifício interior possibilitam uma vista melhor ainda. Nota-se uma abertura à esquerda, mas qualquer entrada sempre foi fortemente guarnecida e defendida. Hoje, em tempos de paz, o Forte é uma atração turística, portanto as portas permanecem abertas várias horas ao dia.

A fotografia esconde o tamanho da fortificação, que na realidade não ocupa uma grande área. O que imagem transmite é a ideia de intransponibilidade para quem está de fora. Este sempre foi o objetivo da arquitetura de defesa. 
Figura 7 - Detalhe do Forte de São Diogo (Salvador - BA)

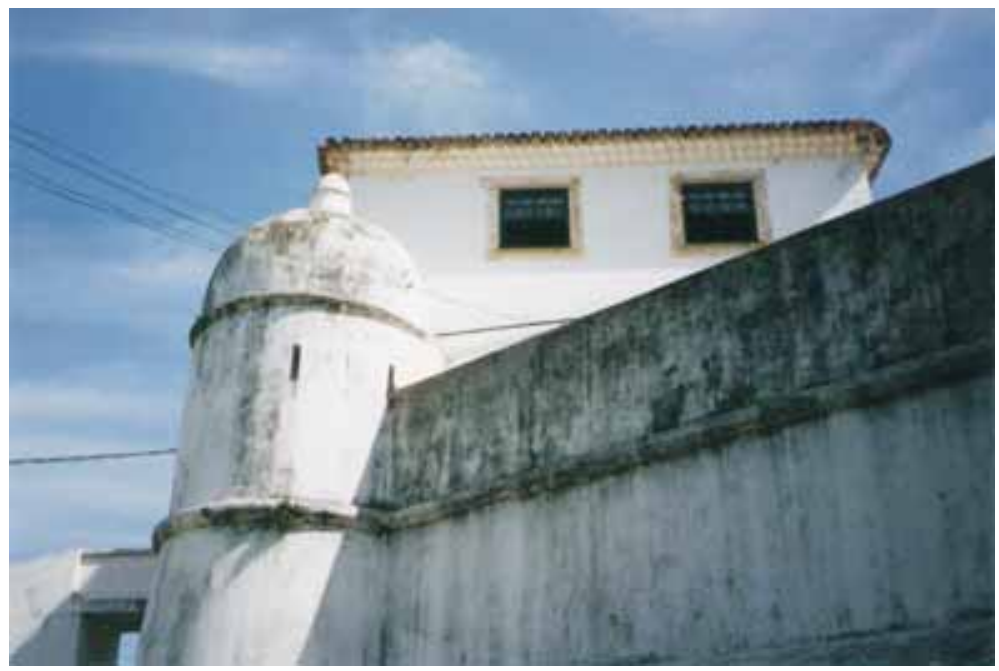

Fotografia: José de Arimathéia C. Custódio (janeiro de 2005) Fonte: Acervo pessoal do fotógrafo

O interior da Igreja do Mosteiro de São Bento de Salvador é a imagem da figura 8. Apesar de a fotografia não ter som, a visualização da imagem torna difícil imaginar que não seja um lugar de absoluto silêncio, especialmente considerando que a fotografia mostra muito poucas pessoas em seu interior, pois não era horário de missa ou outro ofício. De dimensões grandiosas, a Igreja se projeta realmente como um outro mundo, fora do tempo e do espaço seculares. Estar entre suas paredes é estar protegido do mundo exterior, e tudo o que se vê à volta são signos religiosos, bíblicos, voltados à contemplação e salvação da alma.

Na figura 9, nota-se a amplidão do espaço interno do Forte Orange, em Itamaracá (PE). A entrada é por um corredor em que se vê partes em ruínas, até que se chega ao enorme pátio interior. Na imagem, à direita, percebe-se uma rampa. Existem quatro no Forte, e cada uma leva ao nível superior, mais alto que os telhados à vista, e às guaritas remanescentes. Logo atrás dos coqueiros vistos na fotografia, está o mar. No fundo, estão lojinhas e uma espécie de sala de informações turísticas. Mais uma vez, é fácil sentir um isolamento do mundo exterior. Do nível superior, é possível 
vigiar. No pátio interno, há espaço para tudo: exercícios militares, práticas esportivas, festejos religiosos e populares, ou simplesmente uma fuga do barulho de fora.

Figura 8 - Igreja do Mosteiro de São Bento (Salvador - BA)

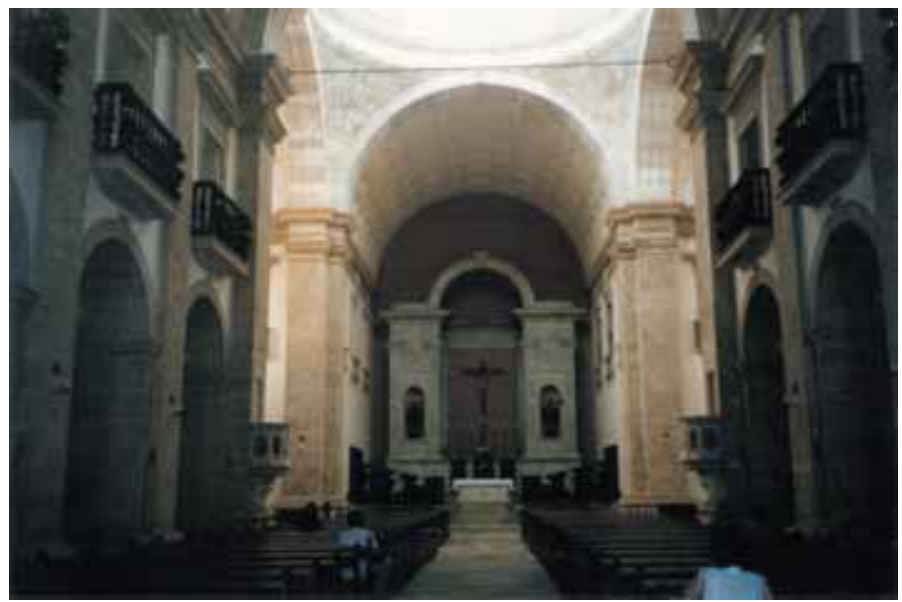

Fotografia: José de Arimathéia C. Custódio (janeiro de 2005) Fonte: Acervo pessoal do fotógrafo

Figura 9 - Pátio interno do Forte Orange (Ilha de Itamaracá - PE)

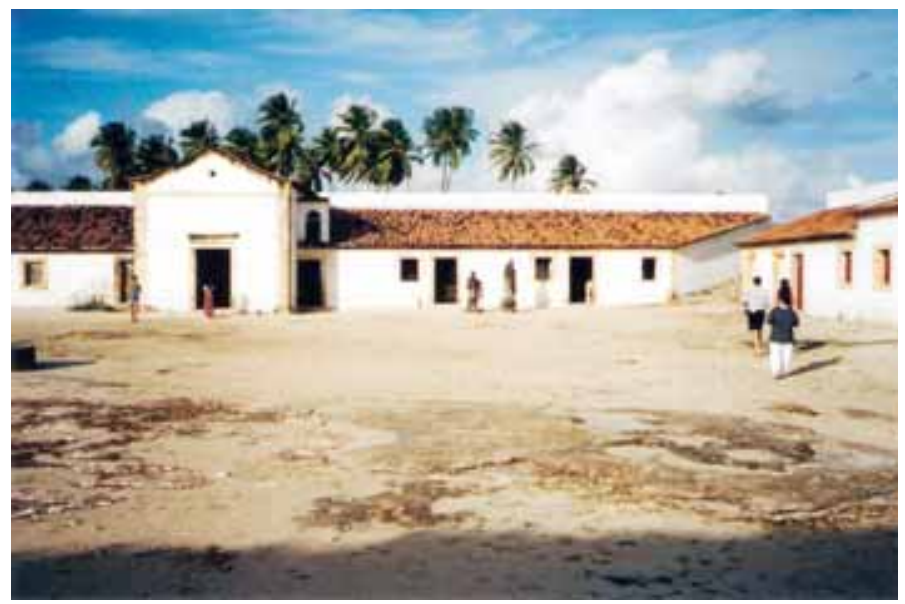

Fotografia: José de Arimathéia C. Custódio (julho 2000) Fonte: Acervo pessoal do fotógrafo 


\section{Considerações finais}

O Brasil não teve Idade Média. Mas os primeiros colonizadores portugueses que chegaram aqui traziam forte herança cultural do medievo. Esta herança ainda está viva nos festejos religiosos populares do interior do país. Mas, nos primeiros séculos de ocupação do território de Pindorama, a arquitetura também foi uma expressão desta herança. Preocupados com a defesa das novas terras, os portugueses construíram uma série de fortificações ao longo da costa atlântica e também no interior, em pontos estratégicos, como o rio Amazonas e a fronteira com a Bolívia. Era o poder imperial ostentando seu poder diante dos outros conquistadores de terras europeias. Um poder político, territorialista e mercantilista.

Ao mesmo tempo, e igualmente, as construções coloniais religiosas foram erguidas na Terra de Santa Cruz para demarcar a soberania da Igreja Católica. E assim como as fortalezas militares defenderiam o território de invasores gananciosos, as igrejas e conventos seriam uma fortaleza contra pagãos e hereges, e em defesa da fé católica. Tanto a arquitetura militar quanto eclesiástica se voltaram, no período colonial - sobretudo nos dois primeiros séculos de ocupação - para a defesa da civilização luso-católica. Não por acaso os jesuítas estavam entre os primeiros religiosos a desembarcar nas terras alcançadas pelos portugueses. A Ordem foi fundada em 1540 pelo espanhol Inácio de Loyola, que era militar, e os membros desta Ordem eram considerados Soldados de Cristo, num ideário que recuperava os princípios cruzadistas de séculos anteriores.

Uma visita atenta a estas construções históricas, tombadas pelo Patrimônio Histórico e Artístico Nacional, é capaz de fazer visualizar a lógica arquitetônica dos dois tipos de edificações - militares na estratégia, espirituais na simbologia. Pois, para os colonizadores portugueses, defender sua casa era defender sua fé, e vice-versa. É por isso que, tanto num mosteiro em Salvador (já cercado pela cidade) quanto numa fortaleza em Niterói, o visitante se sente isolado do espaço e do presente, para viver - ao menos temporariamente, através dos signos ainda vivos - um 
outro tempo e lugar. Esta é a mensagem que os signos arquitetônicos coloniais brasileiros transmitem. Esta é a história que eles testemunharam e contam a cada um que passa diante de seus sólidos muros.

\section{Referências}

ARGAN, Giulio Carlo. História da arte como história da cidade. São Paulo: Martins Fontes, 2005.

BAETA, Rodrigo Espinha. $\mathrm{O}$ barroco, a arquitetura e a cidade nos séculos XVII e XVIII. Salvador: EDUFBA, 2010.

CAMPOS, Adalgisa Arantes. Introdução ao barroco mineiro. Belo Horizonte: Crisálida, 2006.

HISTÓRIA da Arte: Maneirismo, barroco e rococó. Barcelona: Folio, 2008.

TENÓRIO, Douglas Apratto; ALMEIDA, Leda Maria de; DANTAS, Cármem Lúcia. Arte sacra em Alagoas: um tesouro da memória. Brasília: Senado Federal, 2006.

TIRAPELI, Percival. Arte colonial: barroco e rococó. São Paulo: Companhia Editora Nacional, 2006. (Coleção Arte Brasileira). 